http://dx.doi.org/10.5209/rev_ARAB.2011.n30.37838

ÁREA ABIERTA N 30. NOVIEMBRE 2011

Referencia: AA30.1111.152

"El legado del hombre que se tomó la publicidad en serio: Pedro Prat Gaballí Aproximación a sus contribuciones teóricas y profesionales "

AUTORA: Dra QUINTAS FROUFE, EVA. COLUMBIA UNIVERSITY, NEW YORK.

\title{
El legado del hombre que se tomó la publicidad en serio: Pedro Prat Gaballí Aproximación a sus contribuciones teóricas y profesionales
}

The legacy of the man who took advertising seriously: Pedro Prat Gaballí A look at his theoretical and professional contributions 


\title{
Resumen
}

Esta investigación sobre la producción publicitaria y literaria del considerado padre de la publicidad española, Pedro Prat Gaballí, lo revela como un experto publicitario de primer orden que alternó la actividad publicitaria con la docencia académica, el asociacionismo profesional y la redacción de los manuales publicitarios más relevantes del siglo XX, al margen del cultivo de la poesía.

La metodología empleada en la elaboración de este artículo ha sido fundamentalmente la observación documental con el objetivo de compendiar sus contribuciones profesionales y teóricas -manuales, artículos y ponencias- al avance de la publicidad en nuestro país. Complementariamente, se han abordado los títulos que componen su obra poética, una faceta que da muestra de la sensibilidad y versatilidad de esta polifacética figura.

Su actitud proactiva como teórico y técnico publicitario se puso de manifiesto a través de sus constantes reivindicaciones para garantizar la máxima eficacia de la publicidad española. Para ello, promovió la organización de congresos que supusiesen un avance en la disciplina desde un punto de vista científico, de enseñanzas oficiales que permitiesen su estudio estricto y su eficaz aplicación práctica así como de plataformas asociativas que facilitasen la cohesión y la transferencia de conocimientos en el sector, dotando a la publicidad española de una rigurosa base teórica y de visibilidad ante la sociedad.

En definitiva, su ingente legado lo erige en un referente esencial de la historia publicitaria española que abogó por la dignificación de la profesión publicitaria aportando tratados y artículos que proporcionaron a la disciplina un sólido corpus teórico de carácter científico.

Palabras clave: Prat Gaballí, historia de la publicidad española, Veritas, OESTE.

\begin{abstract}
Pedro Prat Gaballi is considered to be the father of the Spanish advertising industry and this analysis of his advertising and literary output shows him to be an advertising guru of the highest order. He combined his work in advertising with academic teaching, professional associations and the writing of some of the 20th century's most important manuals and textbooks on the advertising industry. He was also a keen poet.

The methodology used in preparing this article has been primarily documentary observation with the aim of demonstrating his theoretical and professional contributions - books, articles, papers and presentations - to the advance of the Spanish advertising industry. Additionally, we have looked at some of his poetry works, another of this multifaceted figure's talents, which demonstrates his sensitivity and versatility.

He had a proactive approach to the theory and techniques of publicity and this is reflected in his constant insistence on ensuring that the advertising in Spain was as efficient as possible. To this end, he promoted the organization of congresses so as to advance the discipline from a scientific standpoint and he campaigned for officially recognized training to allow the subject to be properly studied and effectively put into practice. He was also a strong proponent of industry associations to facilitate cohesion and intra-sector knowledge transfer. These all meant that the advertising industry in Spain was built on strong theoretical foundations and that it was highly visible to the public.

In summary, his enormous legacy is an essential reference point in the history of Spanish advertising; he fought to bring dignity the profession through his discourse and articles and bestowed the discipline a solid body of scientific theory on which to build.
\end{abstract}

Key words: Prat Gaballi, history of spanish advertising, Veritas, OESTE. 


\section{Introducción}

Al citar a los técnicos publicitarios pioneros en España, un nombre destaca especialmente entre los demás: Pedro Prat Gaballí, el maestro por excelencia de la publicidad española. No sólo fue un teórico que publicó novedosos manuales que trataban de sistematizar la actividad publicitaria, sino que también fue gerente, director técnico y fundador de agencias de publicidad legendarias como Veritas y OESTE. En este sentido, Rául Eguizábal señalaba la significación de Prat Gaballí como introductor de la publicidad técnica en España en los siguientes términos:

Mucho debe en España, el nacimiento de esta publicidad moderna a la clarividencia pero también a los conocimientos especializados de Pedro Prat Gaballí, introductor de la publicidad técnica en España, que, como demuestran sus escritos, tenía una idea bastante dilatada de los saberes publicitarios y en especial de los engendrados en América del Norte cuyas publicaciones seguía con avidez. Aunque, desde el dominio de la técnica, supo aprovechar su sensibilidad de poeta y de hombre de gran cultura y hacerse con los servicios de algunos de los mejores artistas comerciales de su época. ${ }^{l}$

Estamos ante un profesional completo, que combinó la teoría con su aplicación práctica y simultáneamente, complementó el ejercicio profesional con la docencia. Son exiguos los autores que muestran esta poliédrica actividad que indudablemente enriqueció todas las facetas a las que se dedicó: docente, comercial de productos de perfumería, director de agencias de publicidad, fundador de revistas especializadas y de asociaciones del sector, conferenciante, publicitario, poeta y autor, pero ante todo, un pionero, tal como se manifiesta a continuación:

Fué [sic] el primero en todo. El primero en nuestro país que descubrió a través de su insaciable y juvenil curiosidad, la existencia de unas nuevas técnicas llamadas "advertising". El primero en sistematizarlas escribiendo varios libros sobre ellas. El primero en profesarlas, enseñándoselas a los demás. El primero que montó grandes agencias técnicas en España: Primero la de Veritas, en Madrid. Y luego, después de la guerra, ese leader de publicidad técnica que fué [sic] Publicidad Oeste.2

En efecto, Prat Gaballí ostentó un papel preponderante en cada uno de los elementos que propiciaron el proceso de tecnificación de la publicidad española que tuvo lugar a lo largo del primer tercio del siglo XX: la aparición de los primeros cursos y manuales sobre la disciplina, el surgimiento de los primeros profesionales y agencias técnicas, el nacimiento de un nuevo concepto de publicidad así como la organización del asociacionismo profesional. ${ }^{3}$

Paradójicamente, esta figura de primer orden que impulsó el desarrollo de la publicidad científica y técnica en España -tanto a nivel teórico como práctico- ha sido parcialmente ignorada tanto en el ámbito de la docencia universitaria como en la literatura académica sobre la materia, salvo honrosas excepciones, que aún así constituyen una exigua minoría. Por ello, el principal objetivo de este artículo es rendir tributo y mantener viva la memoria de este prócer de la publicidad española que, quizás por su posicionamiento ideológico tras la guerra civil española, ha sido relegado a un imperdonable olvido.

\section{Metodología}

El objetivo principal de esta investigación es compendiar la actividad profesional de Pedro Prat Gaballí para posteriormente realizar una taxonomía de las aportaciones teóricas y profesionales de este autor a la disciplina publicitaria. Este objetivo de categorización ha determinado fundamentalmente la estructura de esta investigación que se organiza en los siguientes apartados: bosquejo biográfico, formación, docencia y asociacionismo profesional, actividad profesional y obra publicitaria y poética (epígrafe en el que se condensan sus manuales, sus artículos en publicaciones y su obra poética), conferencias y ponencias, finalizando con las consiguientes conclusiones. Para ello, la herramienta metodológica empleada fundamentalmente en este artículo se ha basado en la observación documental.

Con la finalidad de elaborar un compendio de índole cronológico-histórico, se procedió a la revisión de una determinada selección bibliográfica y hemerográfica del período histórico correspondiente con la existencia del autor-desde 1885 hasta 1962- que fue complementada con el estudio de fuentes secundarias más próximas a la actualidad. Por tanto, para poder sustentar las afirmaciones teóricas de esta investigación se han empleado prioritariamente fuentes documentales de carácter bibliográfico y hemerográfico.

${ }^{1}$ EGUIZÁBAL, Raúl. “El arte al servicio de la técnica”, Publifilia, nº 6 (2002), pp. 65-68, p. 65.

2 IZQUIERDO, Francisco. "Mi personaje inolvidable Don Pedro Prat Gaballí", Control de Publicidad y Ventas, $\mathrm{n}^{\circ} 235$ (1982), pp. 7-9, p. 9.

3 ANDRÉS, Susana de. "Asignatura, contenido editorial y empresa. La publicidad en los preludios de la Guerra Civil", Publifilia, no 6 (2002), pp. 19-36, p. 19. 


\section{Bosquejo biográfico}

Pedro o Pere Prat Gaballí4 11 de enero de 1885 - 6 de diciembre de 1962) nació en Pineda de Mar, una población marinera del Maresme barcelonés, en el seno de una familia burguesa, fruto del matrimonio entre el catedrático de matemáticas Pere Prat y Adelaida Gaballí. Su hermana menor Luisa Prat Gaballí nació en 1896 y se dedicó fundamentalmente a la enseñanza siendo la fundadora de la Academia Prat.

En 1911, Pedro Prat Gaballí contrajo matrimonio con Ernestina Ballester en su localidad natal. Seis años después, nació su primer hijo, Jordi Prat i Ballester - escritor y editor que acabará siendo consejero delegado de la Editorial Hispano Europea- y posteriormente, su segunda hija, Mercé. Falleció a los 77 años en su casa situada en el barcelonés Paseo de Gracia, esquina Valencia.

Quienes lo conocieron destacaban su exquisita educación y su bondad como rasgos característicos de su forma de ser. Francisco Izquierdo, un cercano colaborador de Prat-director del departamento técnico de la agencia de publicidad OESTE- describía del siguiente modo su fisonomía: "[...] un hombre suave, pequeñito, de ojos inmensamente azules, con un planchado cabello blanco y una sonrisa bondadosa y cordial". ${ }^{5}$ A nivel profesional, su propio hijo Jordi Prat destacaba el profundo sentido de autoexigencia que lo caracterizaba al calificarlo como una persona "[...] esencialmente auténtica. Pero a su vez era un hombre algo triste. No estaba satisfecho... Todas las personas con grandes aspiraciones intelectuales, son hombres tristes. Porque las grandes aspiraciones intelectuales no se cumplen nunca". 6

\section{Formación y primeros pasos en la profesión publicitaria}

Prat Gaballí dedicó más de ocho lustros de su vida a la publicidad, una actividad que despertó su interés desde la infancia, tal y como él mismo rememoraba:

Recuerdo, de los años de mi niñez, y de los primeros de mi juventud, un cartel ilustrado cándidamente, que decía: antes y después de tomar el chocolate; recuerdo unos anuncios primarios del Jabón de los Príncipes del Congo y los textos frenéticos de una campaña de publicidad de los Remedios del Dr. Munyon. Todavía en sueños veo pasar por las Ramblas el célebre bombo de Escuder. ${ }^{7}$

La época publicitaria de la que Prat guardaba sus primeros recuerdos era la del charlatanismo, aquella en la que la publicidad era una actividad profesional frecuentemente cuestionada y percibida con cierto recelo pues no había sido estudiada con seriedad ni rigor científico. Precisamente una de sus principales aportaciones a la disciplina consistió no sólo en dignificar una profesión desacreditada sino también en dotarla del carácter científico del que hasta entonces había adolecido.

Desde 1897 a 1901, estudió y se revalidó en la Escuela Superior de Comercio -situada en la calle Balmes de Barcelona- posteriormente denominada Escuela de Altos Estudios Mercantiles. Sus lecturas favoritas eran las relativas a idiomas, geografía y economía, pero fundamentalmente, aquellas relacionadas con humanidades puesto que, en sus propias palabras: "[...] espoleaban mi imaginación y sensibilidad, revelándome la grandeza del mundo humanístico, el de la Antigüedad y el Cristiano". 8 Desde que finalizó sus estudios hasta que por fin apostó por su carrera publicitaria en 1911. Prat Gaballí fue un poeta y ciertamente, no dejó de serlo en toda su vida. En esta etapa, se dedicó a ampliar su formación humanística de modo autodidacta así como sus relaciones sociales frecuentando los círculos literarios y artísticos barceloneses, tal como él mismo señalaba: "[...] devoré libros de literatura, arte, crítica, filosofía e historia; realicé mi aprendizaje en las letras y el periodismo; me moví en los cenáculos literarios y artísticos de Barcelona, de principios del siglo".9

Una circunstancia que cambió el rumbo de su vida y marcó el inicio de su carrera comercial fue un hecho fortuito: el descubrimiento del magazine System editado en Nueva York. Esta revista especializada destinada al estudio de los métodos de organización comercial presentaba un lenguaje tan dinámico y vivo que despertó en él un extraordinario interés pues aunaba su formación de carácter humanístico y sus conocimientos comerciales. Ésta fue la revelación de su vocación y el inicio de una vida profesional dedicada fundamentalmente a la publicidad.

A partir de entonces, se formó en el estudio de la bibliografía extranjera y devoró revistas técnicas clásicas como Printer's Ink o Advertising World que le permitieron una constante actualización en la materia. A través de sus páginas, entró en contacto con las aportaciones de técnicos norteamericanos pioneros en la psicología experimental publicitaria como Daniel Starch o Walter Dill Scott. En 1911, una estancia en el

4 Su auténtico segundo apellido era Jabal lí, tal como firma en sus tempranas obras poéticas.

5 IZQUIERDO, Francisco. "Mi personaje inolvidable Don Pedro Prat Gaballí", Control de Publicidad y Ventas, $\mathrm{n}^{\circ} 235$ (1982), pp. 7-9, p. 8.

6 "Pedro Prat Gaballí en el recuerdo. Jordi Prat Ballester: La fidelidad a un nombre", Control de Publicidad y Ventas, núm. 235, p. 25.

7 GARRIGA, Jordi. “Veinte años después”, Control de Publicidad y Ventas, no 235 (1982), pp. 13-21, p. 13.

8 PRAT GABALLÍ, Pedro. Publicidad Combativa, Labor, Barcelona, 1959, p. XII.

9 PRAT GABALLÍ, Pedro. Publicidad Combativa, Labor, Barcelona, 1959, p. XII. 
Alexander Hamilton Institute de Nueva York10 le proporcionó una apertura de horizontes y una perspectiva internacional que el resto de profesionales españoles carecía.

Como ya hemos adelantado, el año 1911 fue clave en su trayectoria profesional. Por entonces, Prat Gaballí estaba finalizando el encargo de un diccionario enciclopédico para el impresor y editor Joaquim Horta cuando tuvo la oportunidad de planificar y ejecutar su primera campaña de publicidad -articulada mediante publicidad directa y artículos periodísticos- para lanzar al mercado este producto editorial. Debido a la atracción irresistible que ejercía en su ser la profesión de publicitario, tomó entonces una decisión que cambiaría el rumbo de su existencia y, en último término, el de la historia de la publicidad española. En definitiva, esta campaña significó el fin de su vocación literaria -su "harakiri literario"11, tal como él lo denominaba familiarmente- y marcó el inicio de su dedicación a esa actividad por entonces nueva y desconocida a la que decidió entregarse por completo asumiendo los riesgos inherentes. No obstante, en su primer contacto con la profesión no obtuvo el éxito deseado debido al clima de incomprensión y escepticismo generalizado que rodeaba a la publicidad, tal como él mismo reconocía: "[...] mis palabras eran oídas como las de un hombre de la luna". ${ }^{2}$

Estos inicios se caracterizaron por luchas y sinsabores ante una profesión casi inventada, que no hicieron mella en el espíritu perseverante y entusiasta de Prat Gaballí, tal como se reflejaba en sus propias palabras: "Pero yo no había nacido para desanimarme y, en el umbral de los treinta años, un hombre entero que sabe lo que quiere no se da fácilmente por vencido". ${ }^{13}$ En este sentido, Prał Gaballí extraía una moraleja de su propia biografía, a modo de consejo para las nuevas generaciones de publicitarios: "[...] para merecer respeto en una profesión, no hay que entrar en ella con impaciencas [sic] y sin una gran voluntad de vencer obstáculos". ${ }^{14}$ Y, efectivamente, su trayectoria constituye la mejor muestra de que nunca se rindió ante las adversidades.

Prat declaraba haberse sentido, en muchas ocasiones, como un profeta que predicaba en el desierto, tal como expresaba en los siguientes términos: "[...] al cumplirse los 50 años de mi primera campaña publicitaria y recordar este medio siglo de vocación y profesión, tengo la sensación de haber predicado en el desierto. Si de mí alguien dice que es aquel señor que se tomaba la publicidad en serio, tendrá razón". ${ }^{15}$ En efecto, entre su legado, figuran los tratados publicitarios más innovadores y relevantes del siglo XX que lo confirman como el primer español que se tomó la publicidad en serio, tal y como quería ser y será recordado siempre.

\section{Docencia y asociacionismo profesional}

Sus primeras incursiones en el ámbito docente tuvieron lugar en 1915 por iniciativa de la Cámara de Comercio y Navegación de Barcelona. ${ }^{16}$ La vinculación entre Prat Gaballí y la corporación de la Cámara de Comercio se extendió a lo largo de toda su vida e incluso durante cuatro años, tomó parte en la redacción de las memorias de esta institución. La Cámara apoyó desde sus inicios gran parte de los cursos y actividades dedicados a la divulgación de la publicidad. Rafael Bori señalaba que esta institución se caracterizó siempre por su apoyo incondicional a todo aquello que representaba progreso en el ámbito publicitario, tal como se extrae de sus palabras: "[...] la Cámara de Comercio y Navegación, que siguiendo la tradición marcada en su ilustre abolengo de patrocinadora de todo cuanto represente progreso técnico comercial". ${ }^{17}$

En 1915, la Cámara como continuadora de la labor de promoción económica de la antigua Junta de Comercio, organizó por primera vez en España un curso denominado Clases de enseñanza mercantil destinado a la impartición de los preceptos de la publicidad científica. Las Clases de enseñanza mercantil constaban, fundamentalmente, de cuatro asignaturas: organización comercial y técnica de los negocios sobre mercancías (Profesor Serra y Pages); la prosperidad en la producción en España (Profesor Vidal); estudio de documentos mercantiles (Profesor Félix Escalas) y armamentos marítimos (Profesor Soldevilla) ${ }^{18}$; asignaturas a las que se añadió la publicidad científica de Pedro Prat Gaballí y otras como, por ejemplo, una asignatura relativa al comercio con Latinoamérica y los medios para acrecentarlo.

Así, fue en 1915 cuando Prat Gaballí -apadrinado por Bartolomé Amengual i Andreu, por entonces secretario de la Cámara de Comercio- divulgó su vasto conocimiento sobre la técnica de la publicidad a través del emblemático curso Una nueva técnica: la publicidad científica ${ }^{19}$ que tuvo lugar en la sede de la Casa Lonja

10 VV.AA. Enciclopedia Universal Ilustrada Europeo Americana, Hijos de Espasa Editores, Barcelona, 1922, Tomo XLVI, p. 1279. Entrada: Prat Gaballí, Pedro.

11 PRAT GABALLÍ, Pedro. Publicidad combativa, Labor, Barcelona, 1959, p. XII.

12 Ídem.

13 Ídem.

14 Ibídem, p. XV.

15 GARRIGA, Jordi. “Veinte años después”, Control de Publicidad y Ventas, no 235 (1982), pp. 13-21, p. 21.

${ }^{16}$ Hoy en día, Cámara Oficial de Comercio, Industria y Navegación de Barcelona.

17 VV.AA., Curso de Publicidad y Organización, Cultura, Barcelona, 1928, p. 8.

18 GARRIGA, Jordi. “Veinte años después”, Control de Publicidad y Ventas, nº 235 (1982), pp. 13-21, p. 15.

19 Tal como figuraba en el programa, este curso se desarrollaría en seis lecciones cuyo horario de clase sería los lunes de 8 a 9 de la noche. El coste de la matrícula para asistir a esta asignatura era de 2,50 pesetas, al igual que las restantes 
de Barcelona, conocida como la Casa Lonja del Mar, convirtiéndose en el primer docente de la materia en nuestro país. Resulta de gran interés, por su valor histórico, la trascripción de las cartas que Prat remitió a Bartolomé Amengual antes de impartir su asignatura pues revelan rasgos de su personalidad como su responsabilidad o su perfeccionismo, y al mismo tiempo, dan muestra del desafío que la actividad docente suponía para él:

Barcelona, 15 de septiembre de 1915.

Sr. D. Bartolomé Amengual.

Muy Sr. Mío de mi mayor consideración:

Con objeto de hablar de mis proyectadas conferencias sobre publicidad, tendré el gusto de pasar a saludarle en esa Secretaría el próximo sábado, día 18, a las 4 de la tarde, salvo el caso de que usted tenga a bien señalarme día y hora a su comodidad. Le presentaré el sumario completo del Cursillo de seis conferencias desarrollando este tema: "Una técnica nueva. La Publicidad Científica".

En un papel aparte encontrará usted algunos temas que se me han ocurrido recordando la pregunta que se sirvió usted hacerme. Si no le aprovechan buscaré otros. Perdone que no le haya escrito antes; una enfermedad de mi esposa, que se halla en el campo, me ha obligado a estar ausente.

Le saluda con el respeto a su afmo. s. q. e. s. m.

(firma ilegible) S/C. Gerona, $84-4^{\circ} 1^{\text {a }} .20$

En la siguiente misiva escrita el 10 de octubre de 1915, Prat Gaballí comenta a Amengual aspectos puntuales como son los fallos en la prueba de impresión del programa y otros detalles de carácter técnico:

Barcelona, 10 de octubre de 1915.

Sr. D. Bartolomé Amengual.

Muy distinguido Señor:

Tengo el gusto de devolverle corregida la prueba de impresión de mi programa. Como verá, he añadido al principio de los párrafos tercero y cuarto la palabra MEDIA (de los medios), que se han comido en la imprenta, y que tengo interés en que no se excluya por ser voz técnica empleada en todos los trabajos de Publicidad, cualquiera que sea el idioma en que estén escritos.

Les agradeceré que tan pronto como haya señalado la fecha en que he de empezar mis explicaciones, tenga la bondad de comunicármela, a fin de que pueda ultimar mi labor sin precipitación. También le suplico me diga a quién debo dirigirme para que me haga los clisés para las proyecciones. Le da expresivas gracias por todo y le saluda con el mayor respeto su afmo. s. q. e. s. m., (Firma ilegible)

Posdata: En este momento recibo su atenta (la segunda de hoy). Me parecen bien los días y las horas que usted disponga. Le estimaré sólo no deje de decirme cuanto antes a partir de qué fecha. Tengo tomadas mis medidas para empezar a mediados de noviembre; así, pues, para el caso de que usted disponga empiecen antes los cursos me conviene saber en seguida la fecha fija. Gracias anticipadas. ${ }^{21}$

Por último, en la misiva remitida el día 2 de noviembre de 1915, Prat Gaballí declaraba estar preparado para inaugurar su serie de conferencias:

Barcelona, 2 de noviembre de 1915.

Muy Sr. Mío y respetable amigo:

En contestación a su atenta de hoy, tengo el gusto de comunicarle que estoy preparado para empezar mis conferencias el próximo día 8 y que si no he pasado por esa Cámara para estimar lo de los clisés es porque para la primera conferencia de pura teoría, no serán necesarias proyecciones. Si usted no dispone de otra cosa, cada lunes, al ir a dar mi explicación haré entrega del material para los clisés [sic] de la conferencia próxima. Con este motivo me reitero afectuosamente de Ud. servidor, q.e. s. m. P. Prat Gaballi. ${ }^{22}$

asignaturas del curso. Sin embargo, esta cantidad sería reembolsada a los alumnos que demostrasen un óptimo aprovechamiento del curso, como se establecía en el programa del mismo: "la cantidad total recaudada, junto con otra igual que añadirá la Cámara, se distribuirá en premios a los alumnos que, habiendo asistido con asiduidad, hayan demostrado mayor aplicación y teniendo en cuenta el número de lecciones y el de alumnos de cada clase". PRAT GABALLÍ, Pedro. Una nueva técnica. La publicidad científica, Cámara Oficial de Comercio, Industria y Navegación, Barcelona, 1992, s.p.

${ }^{20}$ Carta mecanografiada reproducida en GARRIGA, Jordi. “Veinte años después”, Control de Publicidad y Ventas, $\mathrm{n}^{\circ} 235$ (1982), pp. 13-21, p. 16.

${ }^{21}$ Carta mecanografiada reproducida en GARRIGA, Jordi. “Veinte años después”, Control de Publicidad y Ventas, n 235 (1982), pp. 13-21, p. 16.

22 Carta mecanografiada reproducida en GARRIGA, Jordi. “Veinte años después”, Control de Publicidad y Ventas, nº 235 (1982), pp. 13-21, p. 17. 
Los autores que han estudiado este tema, difieren en las características exactas de este curso: el investigador Santi Barjau, basándose en las memorias publicadas por la Cámara de Comercio, ${ }^{23}$ apunta que el curso dio comienzo con un total de 41 alumnos matriculados mientras que Garriga establece que fueron 33 las matrículas. ${ }^{24}$

Así, durante el curso 1915-1916, Prat Gaballí impartió 12 conferencias sobre publicidad científica, tal como se recoge en su biografía publicada en L'ensenyament comercial i la formació de vendedors hábils. ${ }^{25}$ Posteriormente, en el marco del V Congreso Internacional de Publicidad celebrado en 1935, en uno de los salones de esta corporación, fue develada una placa conmemorativa como reconocimiento de que allí había sido desarrollado el primer curso de publicidad impartido en España:26

Fueron de fuera, quienes en ocasión del V Congreso de la "Unión Continental de la Publicidad" -no la IAA-, celebrado el mes de abril de 1935 en Barcelona, y organizado por el Publiclub, fundado por PPG en 1922, quienes regalaron una placa metálica enmarcada en caoba que recordaba la efeméride del año 1915, en que la "Cámara de Comercio y Navegación de Barcelona" hubiese instituido en España el primer Curso de Enseñanza de la Publicidad Científica. ${ }^{27}$

En 1917, se publicaron los contenidos de este curso en un volumen titulado Una nueva técnica: la publicidad científica, un manual editado por la Cámara de Comercio de Barcelona que supuso la piedra angular de la bibliografía publicitaria española pues inauguró los estudios de técnica publicitaria en España.

Por otra parte, en el curso académico de 1916-17, Prat Gaballí impartió en 8 conferencias el curso Escuela de vendedores para el Centre Autonomista de Dependents del Comerç y de la Indústria (CADCI) de Barcelona. ${ }^{28}$ En el curso de 1917-18, la Cámara de Comercio contó de nuevo con Prat Gaballí para impartir un nuevo curso de carácter práctico titulado: Ventas por correspondencia y campañas de Publicidad en un total de 30 conferencias. El enunciado de este curso resulta significativo por la innovación y actualidad que supone el estudio de las ventas por correo, que aún hoy en día se ubicaría en la categoría de medios no convencionales.

En 1922, en torno a la figura de Prat Gaballí, se fundó la Asociación de Profesionales de la Publicidad que en 1927 se transformaría en una entidad más amplia con análogos objetivos denominada Publi-Club, en la que Prat Gaballí ostentó un papel clave como presidente y posteriormente como presidente de honor. En el marco del Curso de Publicidad y Organización organizado por el Publi-Club del 21 de mayo al 3 de junio de 1928, Prat Gaballí impartió "Los caminos científicos de la publicidad". En cuanto a su participación en iniciativas corporativas, Prat Gaballí también ostentó el cargo de presidente en el Gremi de Publicitat, al igual que lo habían sido Rafael Roldós, Enrique Vior y Josep M. Fortuny.

En el ámbito estrictamente docente, la disciplina publicitaria comenzaba a dar sus primeros pasos de cara a la institucionalización y oficialización de los estudios en esta materia. En efecto, dos de las principales reivindicaciones de Prat Gaballí al Consejo Nacional de Cultura eran la reorganización de las Escuelas de Comercio del Estado y la inclusión de la enseñanza de la publicidad en los planes de estudios oficiales.

De hecho, fue en septiembre de 1932 cuando la Generalitat de Catalunya decidió reorganizar el Instituto de Estudios Comerciales proponiendo un plan de estudios que comprendía cinco cursos académicos, dentro de los cuales se ubicaba la materia Estudios de Mercado y Publicidad. ${ }^{29}$ En 1933, Prat Gaballí anunciaba que "a

23 Cámara de Comercio y Navegación de Barcelona (ed.). Memoria de los trabajos realizados durante el año 1915, Talleres de Artes Gráficas Henrich y Ca, Barcelona, 1916, p. 151 y Cámara de Comercio y Navegación de Barcelona (ed.). Memoria de los trabajos realizados durante el año 1916, Talleres de Artes Gráficas Henrich y Ca, Barcelona, 1917, p. 129. Citados en BARJAU, Santi. “Los inicios del pensamiento publicitario: Pere Prat Gaballí, Rafael Borí y el ‘Publi Club'. La teoría y la práctica de la publicidad 'racional' en Cataluña entre 1915 y 1939”, Publifilia, nº 6 (2002), pp. 49-64, p. 53.

24 Siguiendo a Barjau, el curso que se inició el 3 de noviembre comenzaba rodeado de cierta polémica pues un sector de los alumnos quería que las clases fuesen impartidas en catalán, motivo por el cual fueron interrumpidas el 3 de diciembre de 1915 y se retomaron el día 10 de febrero de 1916. Barjau sostiene que el curso siguió el programa previsto y finalizó en julio con las lecciones íntegramente en castellano. Aunque Jordi Garriga señala al respecto que se impartieron en ambos idiomas "la Cámara, ecléctica y conservadora, se decidió porque las clases se impartieran simultáneamente en castellano y catalán [...]”. GARRIGA, Jordi. “Veinte años después”, Control de Publicidad y Ventas, n 235 (1982), pp. 13-21, p. 17.

25 PRAT GABALLÍ, Pedro. L'ensenyament comercial i la formació de vendedors hàbils, P. Montaner, Sabadell, 1917.

26 Esta placa fue hallada por Jordi Garriga y Joan Enric Nebot, en un desván de la Cámara de Comercio, un día de otoño de 1971. El 10 de mayo de 1972, con motivo de la celebración en Barcelona del XXI Congreso de la Federación Internacional de Clubs de la Publicidad y del 50 aniversario de la fundación del Club de la Publicidad de Barcelona se descubría una placa conmemorativa de mármol en La Lonja del Mar (Cámara de Comercio Industria y Navegación) de la primera lección técnica sobre publicidad científica que pronunciara en 1915 Pedro Prat Gaballí. Véase GARRIGA, Jordi. “Veinte años después", Control de Publicidad y Ventas, nº 235 (1982), pp. 13-21, pp. 17 y 19.

${ }^{27}$ GARRIGA, Jordi et. al. Pedro Prat Gaballí. 505 verdades publicitarias, Oikos-Tau, Barcelona, 1998, p. 98.

28 PRAT GABALLÍ, Pedro. L'ensenyament comercial i la formació de vendedors hàbils, P. Montaner, Sabadell, 1917.

29 Se diseñó un plan de 5 cursos académicos, divididos en semestres, en el que por primera vez en España un centro oficial 
partir del próximo curso funcionará una cátedra nueva en la Institución de Estudios Comerciales que sostiene la Generalidad de Cataluña. Una cátedra sobre una materia nueva en España, sobre todo en la primera parte de su enunciado: Estudio de Mercados y Publicidad". 30 Precisamente, salió a concurso la provisión de una cátedra de esta materia, que Prat ganó en el estío de 1936 como recompensa a su magisterio, un nirvana profesional que se desvaneció con la irrupción de la guerra civil.31

Por último, cabe destacar que en 1951, pronunció su última lección titulada "La publicidad en el porvenir de la enseñanza mercantil española" en el curso Teoría y Práctica de la Publicidad impartido en la Escuela de Altos Estudios Mercantiles de Barcelona, el centro en el que se había formado.

\section{Actividad profesional}

En 1913, Prat Gaballí ejerció como director de la revista barcelonesa Comercio (cuyo subtítulo era Revista de los negocios modernos) fundada por el impresor Joaquim Horta, que estuvo abocada a una efímera existencia. A pesar de su breve andadura editorial, fue una de las publicaciones españolas pioneras en tratar temas publicitarios. ${ }^{32}$ Esta revista técnica estaba destinada a dar a conocer las modernas orientaciones norteamericanas de incorporación de la psicología a la economía. No obstante, en 1914, Prat había sido sustituido por R. Volart Pons que ejercía como director y había ampliado el rango temático de la revista cuyo contenido no era ya exclusivamente publicitario sino que incluía artículos de temática variada. ${ }^{33}$

Posteriormente, en 1919, dirigió y puso en funcionamiento los engranajes de la empresa de publicidad Famaasociada mediante un acuerdo de joint-venture a la agencia suiza Publicitas, al igual que Helios en Madrid- en la que creó uno de los primeros departamentos técnicos de publicidad, todo un hito pues hasta entonces las agencias eran prácticamente intermediarias entre anunciantes y medios impresos. El propio Prat consideró la creación de esta agencia técnica como un adelanto a los tiempos ante un entorno empresarial poco predispuesto a asimilar técnicas cuya aplicación práctica y beneficios ignoraban, calificándola como "[...] una iniciativa prematura, porque los directores de Empresas no estaban preparados para aceptar unos servicios cuya utilidad desconocían y difícilmente se les podía demostrar". ${ }^{34}$ Paralelamente, fundó la revista Fama -house-organ de la agencia Publicitas- cuyo primer número apareció en junio de 1919 y dejó de editarse a mediados de la década de los treinta.

En 1921, detectando su inexperiencia en la vida práctica del comercio, Prat Gaballí decidió ceder la dirección de la revista Fama, abandonando también sus funciones en la agencia, para ejercer de comercial de una prestigiosa empresa de perfumería española. Durante siete años, desde 1921 hasta 1928, Prat Gaballí fue el representante exclusivo de la Perfumería Gal en la zona de Cataluña y Baleares. Cuando en 1927 se creó el primer Club de Publicidad español, el Publi-Club, del que Prat Gaballí fue fundador y presidente, en las páginas de Pompas de Jabón -la revista órgano privado de Gal- se resumía del siguiente modo la carrera profesional del autor:

No hemos de prodigar elogios a la profunda y amplia labor realizada en materia de Publicidad por el Sr. Prat Gaballí, es "de la Casa", y esto nos impone sobriedad en la expresión. Autor de varias obras de Publicidad (La Publicidad de nuestro tiempo, Una nueva técnica, Publicidad científica, Técnica de Publicidad), y de una no interrumpida campaña periodística, fundó las Revistas técnicas Comercio y Fama y ocupó la primera cátedra española de estudios publicitarios. ${ }^{35}$

Como si de una casualidad del destino se tratase, en 1928, fue llamado por Salvador Echeandía Gal para dirigir la agencia de publicidad cautiva de Gal, Veritas, S.A, en la que alcanzó su madurez profesional. La fructífera colaboración del binomio formado por Federico Ribas -director artístico- y Pedro Prat Gaballí director técnico y gerente- en Veritas tuvo lugar en vísperas de la guerra civil española, desde 1928 a 1935, siendo trágicamente truncada por el conflicto bélico. Veritas supuso la consolidación de una estructura

incluía la asignatura "Estudios de Mercado y Publicidad"; con la máxima duración que podía tener una materia (60 horas lectivas). La asignatura se encuadraba en el segundo curso del plan de estudios, dentro del área docente de "Técnica de gestión de empresas". URL [http://ares.cnice.mec.es/informes/12/contenido/pagina\%2030.htm] [Consultado 08-022011].

30 PRAT GABALLÍ, Pedro. “El estudio de mercados”, Nuevo Mundo, no 2053 (1933).

31 PRAT GABALLÍ, Pedro. Una nueva técnica. La publicidad científica, Cámara Oficial de Comercio, Industria y Navegación, Barcelona, 1992, p.9.

32 Antonio Caro apunta la existencia de dos publicaciones periódicas sobre publicidad previas a Comercio: Gaceta Anunciadora (1902) y Gaceta del Comercio (1911). Véase CARO, Antonio. "Exceso y miseria de la información publicitaria" en EGUIZÁBAL, Raúl y CARO, Antonio (coords.). Medición, Investigación e información de la publicidad, Edipo, Madrid, 1996, p. 162.

33 BARJAU, Santi. "Los inicios del pensamiento publicitario: Pere Prat Gaballí, Rafael Borí y el 'Publi Club'. La teoría y la práctica de la publicidad 'racional' en Cataluña entre 1915 y 1939”, Publifilia, no 6 (2002), pp. 49-64, pp. 52 y 53.

34

35 “El primer club español de publicidad”, Pompas de jabón, nº 6 (1927), pp. 7-8, p. 7. 
profesional básica y representó la culminación de una época en que la técnica publicitaria experimentó notables avances orientándose hacia las directrices de la denominada publicidad científica. En esta etapa, Prat Gaballí dotó a las comunicaciones publicitarias de los emisores comerciales para los que trabajó de una eficacia y de una visión estratégica a largo plazo sin precedentes en la historia publicitaria española, muestra de un rigor y un talante innovador que aún permanece vigente en la actualidad. En el seno de esta agencia, al margen de la gestión y dirección de la empresa, desempeñó simultáneamente funciones de director creativo y redactor publicitario, facetas profesionales desconocidas de gran interés y novedad que han sido señaladas por las profesoras Alvarado y De Andrés. ${ }^{36}$

Por su parte, en Veritas, Ribas se afianzó en el oficio de artista publicitario poniendo de manifiesto su privilegiada comprensión de la moderna técnica publicitaria mediante una concepción progresivamente más técnica y comunicativa. En este sentido, Eguizábal corrobora su relevancia en el ámbito publicitario mediante esta contundente afirmación: "Si hay, en el discurrir de la publicidad en España, alguien que pueda responder cabalmente a la idea de 'artista publicitario', ese es Federico Ribas. [...] Ribas fue el artista publicitario por definición, poniendo en su trabajo, como dijo de él Prat Gaballí 'una atmósfera de agrado a los vehículos o los objetos del comercio material de los hombres'. Y su estilo moderno, sensual y distinguido dibujó una página de oro de la publicidad española"37.

La labor de Prat en Veritas abarca casi ocho años de inagotable actividad, cuando por "razones personales", decidió regresar a Barcelona para fundar una agencia de publicidad que llevaría su nombre establecida en el número 66 del Paseo de Gracia. Sin embargo, la irrupción de la guerra fratricida impidió que Prat Gaballí llevase a cabo este ambicioso proyecto, a juzgar por sus palabras: "Fijé de nuevo mi residencia en Barcelona, fundando una nueva agencia a mi nombre, malograda por la guerra pocos meses más tarde". 38

Antes de embarcarse en la creación de su propia agencia, según las investigaciones aportadas por Barjau, opositó a varias plazas para puestos de trabajo de la Generalitat. En concreto, en 1934, optó al cargo de secretario del Comité de Cine, en pugna con Doménech Jiménez y Ricaredo de Vilches, pero retiró su instancia antes de finalizar el plazo. ${ }^{39}$

En julio de 1939, Prat Gaballí pudo hacer realidad el proyecto empresarial que previamente se había visto frustrado y procedió a la fundación de una nueva agencia de publicidad: OESTE (acrónimo de Organización, Estudios y Servicios Técnicos Especializados) con sede en la Diagonal barcelonesa. Muchos de los anunciantes que confiaron en él en Veritas mantuvieron su lealtad y decidieron apoyarle en esta nueva iniciativa empresarial, siendo Artiach su primer y mayor accionista, secundado por Firestone y Paños Ramos. En la década de los años cuarenta, contó con nuevos socios y una cartera de clientes compuesta por anunciantes de gran potencial como Myrurgia (principal competidor de Gal), Codorníu, Hispania y Jabones Berangé. Posteriormente, en la década de los cincuenta, participó activamente en el lanzamiento de la empresa cervecera San Miguel.

A lo largo de su brillante y dilatada trayectoria profesional, Prat Gaballí abogó por el estudio previo de las condiciones del mercado -producción, distribución y consumo- que garantizó la eficacia de las campañas de publicidad que dirigió.

\section{Obra publicitaria y poética}

\subsection{Manuales publicitarios de referencia}

Sus obras publicitarias más significativas son los siguientes manuales sobre la teoría y técnica de la publicidad: Una nueva técnica: la publicidad científica (1917), Publicidad Racional (1934), El poder de la publicidad (1939) y Publicidad Combativa (1953). Al margen de estos libros, Prat Gaballí realizó diversas aportaciones a varios volúmenes de la enciclopedia El Comerciante Moderno editada por la Editorial Labor: "Correspondencia comercial" (1915) escrito en colaboración con Rottée de la Universidad Comercial de París publicada en el tomo I; "La publicidad de nuestro tiempo" (1915), tomo Il; "Geografía económica de Europa" (1915), tomo IV y "Técnica de la publicidad", tomo VII. Otra de sus obras fue L'ensenyament comercial i la formació de vendedors hàbils (1917).40 Del mismo modo, redactó y dirigió la Enciclopedia Pallas de pequeño formato y asimismo, fue colaborador de la Enciclopedia Espasa.

Prat Gaballí aclaraba que "La publicidad de nuestro tiempo" había sido, por orden cronológico, el primero de sus libros relacionados con la disciplina publicitaria al ser publicado en 1916, no obstante, como formaba parte

\footnotetext{
36 ALVARADO, Ma Cruz y ANDRÉS, Susana de. "El concepto de creatividad en la obra de Pedro Prat Gaballí", Trípodos, $\mathrm{n}^{\circ}$ extra (2006), pp. 13-22.

${ }^{37}$ EGUIZÁBAL, Raúl. "Cuatro siluetas publicitarias”, Academia de la Publicidad, (2009).

URL [http://www.academiadelapublicidad.org/index.php/colaboraciones-actualidad-y-archivo/histórico] [Consultado 15-05-2011].

${ }^{38}$ PRAT GABALLÍ, Pedro. Publicidad Combativa, Labor, Barcelona, 1959, p. XIII.

39 Arxiu de la Diputació de Barcelona, fondo Generalitat, legajo 4.256, expediente 241. Citado en Barjau, Santi. "Los inicios del pensamiento publicitario: Pere Prat Gaballí, Rafael Borí y el 'Publi Club'. La teoría y la práctica de la publicidad 'racional' en Cataluña entre 1915 y 1939”, Publifilia, no 6 (2002), pp. 49-64, p. 57.

${ }^{40}$ PRAT GABALLÍ, Pedro. L'ensenyament comercial i la formació de vendedors hàbils, P. Montaner, Sabadell, 1917.
} 
de la obra enciclopédica El Comerciante Moderno, no se ha considerado como un volumen autónomo. En la segunda edición de esta obra que data de 1922, dicho tratado fue sustituido por otro titulado Técnica de la publicidad. ${ }^{41}$

En 1939, publicó Nuevos principios de correspondencia comercial en la editorial Gustavo Gili. En 1951, se publicó como separata Propaganda y Opinión Pública que sintetizaba el contenido de su discurso inaugural del Círculo Publicitario de Barcelona pronunciado el 16 de octubre de 1950.

Prat Gaballí alcanzó tal estatus como profesional y como autor que llegó a prologar numerosos libros de gran notoriedad como Economía publicitaria42 (1939) de J. W. Taylor y la edición española de Mi vida en la publicidad (1945) de Hopkins ${ }^{43}$ con un texto titulado "Al margen de una experiencia y de una vida".

\section{Una nueva técnica. La publicidad científica (1917)}

En el volumen Una nueva técnica. La publicidad científica,44 Prat recopilaba las enseñanzas impartidas en el curso de la Cámara de Comercio y Navegación previamente señalado. Este manual, que despertó una gran expectación, fue remitido a empresas y particulares asociados a la Cámara de Comercio, así como a las autoridades. Prat Gaballí reconoció el carácter pionero de las enseñanzas contenidas en este manual: "[...] constituyeron el primer tratado original sobre la materia publicado independientemente en lengua española". 45 En efecto, fue la primera obra monográfica sobre la técnica publicitaria escrita en español cuya influencia se extendió hasta Hispanoamérica.

Su título, que califica a la publicidad como científica, sugiere el propósito del autor de fundamentar esta técnica sobre una metodología sistemática, anulando cualquier connotación de improvisación que pudiera asociarse al concepto. Cabe destacar que Prat Gaballí se adelantó a la obra de referencia en la bibliografía científica de publicidad Scientific Advertising (1923) de Claude C. Hopkins, un clásico de la publicidad sistematizada.

Los contenidos de la asignatura impartida por Prat se estructuraban en seis lecciones que constituían los principales apartados del tratado:

1) En la primera lección, de carácter introductorio, estudiaba los factores psicológicos a los que apela la publicidad en los siguientes epígrafes: Introducción al estudio de la publicidad. El curso de la Psicología. La atención y la memoria. Los sentimientos y emociones. La sensibilidad y la inteligencia. El interés. La voluntad. Las leyes del contraste. La sugestión. Experiencias y ejemplos. Períodos de la Publicidad.

2) La segunda lección profundizaba en los elementos visuales (gráficos y tipográficos) a tener en cuenta en la composición de un anuncio gráfico: Técnica de la Publicidad. Componentes de un anuncio. Solución práctica de los problemas que plantea la Psicología. La construcción de un anuncio. Del "display". Elementos tipográficos. Elementos gráficos. De la visualidad. De la armonía. De la originalidad.

3 y 4) Las lecciones tercera y cuarta, ambas bajo el epígrafe genérico de Media trataban de sintetizar las características de los medios publicitarios existentes por entonces. La lección tercera incluía los siguientes ítems: Media: La Publicidad en manos del público: la prensa, el impreso, la correspondencia, cupones primas, objetos de reclamo. La publicidad abierta y la publicidad cerrada. Formas de los medios. Análisis de su acción. Del "Follow up system". Y la lección cuarta hacía referencia a las características de los medios publicitarios exteriores así como de la publicidad internacional mediante los epígrafes indicados a continuación: Media: La Publicidad en lugares públicos: carteles, anuncios murales, placas, enseñas, rótulos, la Publicidad luminosa; hombres "sandwich", hombres anuncios, vehículos, artificios varios. De la Publicidad llamada en España norteamericana; breves observaciones sobre las costumbres y el carácter de los pueblos. Formas de los medios. Análisis de su acción.

5) La quinta lección estaba dedicada exclusivamente a las campañas publicitarias: Campañas de Publicidad. Organización administrativa. Ensayos. Presupuesto. Cálculo probabilidades. La idea central, fuera de venta. Análisis de los elementos que han de componer una campaña de Publicidad. Las circunstancias y las épocas. Las características de cada negocio. Los peligros de copiar las campañas extranjeras. Exposición de algunas campañas.

6) Finalmente, la sexta y última lección se centraba en los rasgos característicos de la incipiente actividad publicitaria española: La Publicidad en España. Antecedentes. La publicidad balbuciente. Los aciertos individuales. Influencia de otros países. Tipos de publicidad nacional. Cómo se hace la publicidad en España. La imprevisión, germen de fracasos. Los diarios, falta de método en la distribución de los anuncios. Acción de las agencias. Algunas ideas sobre cifras. Conclusión.

En definitiva, el mérito de los libros publicados por Prat Gaballí radica en su enfoque teórico-práctico ya que condensan estudios y teorías complementados con su experiencia a lo largo de la vida profesional, lo cual

41 PRAT GABALLÍ, Pedro. Publicidad Combativa, Labor, Barcelona, 1959, p. XII.

42 TAYLOR, F.W. Economía publicitaria, Juventud, Barcelona, 1939.

43 HOPKINS, Claude C. Mi vida en la publicidad, Dalmau y Jover, Barcelona, 1945.

44 Publicada en 1917 y reeditada a modo de homenaje en 1992.

45 PRAT GABALLÍ, Pedro. Publicidad Combativa, Labor, Barcelona, 1959, p. XI. 
enriquece notablemente el resultado. Aunque normalmente evitaba mencionar directamente las empresas, las marcas o las campañas a las que hacía alusión, en sus obras figuran anuncios gráficos y analiza campañas publicitarias de empresas reconocibles. Por ejemplo, en El poder de la publicidad relata la gestación y desarrollo de una campaña de publicidad social de una fábrica de perfumería que produce una Pasta X. Por la repercusión que tuvo esta campaña, es evidente que la empresa perfumista es la Perfumería Gal y la Pasta $X$ no es otra que el dentífrico Pasta Dens.

\section{Publicidad Racional (1934)}

En 1934, Prat Gaballí publicó su obra Publicidad Racional tras haber acumulado y asimilado la suficiente experiencia profesional en sus siete años al frente de la dirección técnica de la agencia Veritas. En ella había adquirido un gran bagaje como gestor de notorias campañas publicitarias para importantes anunciantes españoles como Artiach, Codorníu, Elgorriaga, Massó, Floralia y por supuesto, la Perfumería Gal. Este volumen, considerado como la carta magna de la publicidad española fue distinguido con el premio Conde de Lavern otorgado por la Cámara de Comercio y Navegación de Barcelona. Sin duda alguna, esta publicación editada por Labor se erigió en uno de los manuales publicitarios más rigurosos que se habían publicado en España hasta la fecha.

Este libro resultó ser un auténtico éxito cuyos ecos resonaron más allá de nuestras fronteras, siendo elogiado en publicaciones de la talla de la francesa Publicité, la norteamericana Printer's Ink y la británica Commercial Art and Industry. Sus ventas alcanzaron tales índices que la primera edición se agotó en 1949, con la particularidad de que el último millar se había vendido mucho más rápido que los millares precedentes debido al creciente interés que despertaron, en España y Hispanoamérica, los estudios sobre la técnica publicitaria. Prat Gaballí manifestó su pretensión de reeditarlo en los años cincuenta, pero en su lugar, emprendió la elaboración de una nueva obra con contenidos actualizados que llevó por título Publicidad Combativa publicada por primera vez en 1953, a la que haremos referencia a continuación.

\section{Publicidad Combativa (1953)}

En un principio, el editor de Publicidad Racional encomendó a Prat una revisión del libro para preparar una reedición. En lugar de revisarlo, Prat Gaballí decidió acometer la tarea de redactar un nuevo manual por varias razones: en primer lugar, habían transcurrido casi cuatro lustros desde la publicación de Publicidad Racional en los que se habían sucedido la guerra civil y la segunda guerra mundial; su experiencia vital y profesional se había enriquecido notablemente con la ejecución de nuevas campañas y sus continuos viajes a Estados Unidos; las tendencias y modas se habían modificado en el transcurso de veinte años y además, la evolución de la publicidad en España y en América había sido sustancial y por ello, habría que reflejar los cambios metodológicos tanto en técnica y como en estética en un nuevo ejemplar. ${ }^{46}$ Por todo ello, Prat Gaballí dio por caducado el anterior libro y ofreció al editor esta nueva publicación cuya primera edición vio la luz en 1953 -agotada transcurridos seis años-, saliendo a la venta la segunda edición en 1959. Este tratado fue exaltado por la prestigiosa publicación Printer's Ink como "one of the best advertising books in any language". ${ }^{47}$

A través de estos manuales publicitarios siguió la estela de investigaciones emprendidas en Alemania y Estados Unidos cuyo fin era fundamentar científicamente la publicidad desde un punto de vista psicológico.

\section{Otras contribuciones}

En los últimos años de su existencia, Prat Gaballí, siempre atento a la evolución de la investigación publicitaria, dirigió una colección titulada Biblioteca de la Dirección de Empresas para la editorial Hispano Europea en la que dio a conocer algunas de las obras estadounidenses más relevantes de la materia. Su labor consistía en seleccionar, supervisar y, en ocasiones, prologar títulos como por ejemplo Investigaciones de las motivaciones del consumidor (1960) de H. Henry; Cómo se comportan los consumidores (Psicología del gasto) (1962) de S. H. Britt; Relaciones Públicas (1958) de Nielander y Miller o Cómo anunciar para TV (1958) de C. H. Adnew y N. O'Brien. Esta colección continuó su andadura editorial tras el fallecimiento de Prat Gaballí.

Tras su muerte acontecida en 1963, se publicó el libro Thesaurus que compilaba terminología dinámica de las nuevas técnicas comerciales recopilada por un equipo de la Biblioteca de la Dirección de Empresas dirigido por V. F. Bielsa (Hispano Europea, Barcelona) con prefacio de Prat Gaballí. Por último, el 24 de junio de 1963, se publicó "Primeros pasos" de Prat Gaballí, un número extraordinario de Publi-Club editado con ocasión del XIII Congreso de la F.I.C.P. de Barcelona.

\footnotetext{
46 Prat Gaballí sostenía que los principios técnicos no habían variado esencialmente aunque sí los aspectos metodológicos pues habían surgido nuevas técnicas de investigación, identificación y verificación; así como derivaciones de la publicidad y nuevos medios. PRAT GABALLÍ, Pedro. Publicidad Combativa, Labor, Barcelona, 1959, p. XIV.

47 Printer's Ink, (08-04-1955), p. 92.
} 


\subsection{Artículos en publicaciones periódicas}

Prat publicó sus reflexiones y reivindicaciones sobre la disciplina publicitaria tanto en revistas especializadas como en publicaciones de información general. El rango temático abordado en estos escritos es muy amplio, abarcando desde el análisis económico de los motivos de la crisis de 1929 a la propugnación de un arte publicitario sintético y de alto valor psicológico, pasando por la exaltación de una campaña de publicidad social desarrollada en España o la importancia de la mujer como target prioritario en las comunicaciones publicitarias.

Entre 1913 y 1914, Prat Gaballí publicó sus primeros artículos sobre materia publicitaria en la pionera revista Comercio, editada por Joaquim Huerta, una publicación "[...] en cuyas páginas se daba categoría a los problemas de publicidad y venta, esbozando en ellas una técnica que algunos años antes había nacido en América, que acababa de hacer su entrada en Europa por Inglaterra y Alemania, y que hoy es cultivada con intensidad en Francia y todos los demás países progresivos, incluyendo en ellos España", 48 en palabras del propio Prat. Para el primer número de esta revista escribió "La información mercantil en España"49 y para el tercer número "Enseñanzas de una Exposición Internacional de la Publicidad de Londres de 1914 ".50 Posteriormente, colaboraría en el periódico El Día Gráfico en una sección quincenal titulada "Técnica de negocios" iniciada el 10 de junio de 1914 para la que redactó artículos como "El estímulo y la técnica" o bien "Sobre publicidad". Esta sección se anuló para dar cabida a información sobre la guerra europea; en particular, Barjau señala que la última intervención que ha localizado de Gaballí en esta publicación data del 25 de julio de $1914 .{ }^{51}$

En la revista Fama -que dirigió de 1919 a 1921- publicó "El arte de Roberto Cares"52 y en octubre de 1923, el artículo "Demasiados anuncios". 53 Barjau resume del siguiente modo la labor de Prat Gaballí al frente de la dirección de esta revista: "A lo largo de las páginas de la publicación, el tratadista informaba de aspectos concretos de la práctica de la publicidad, daba a conocer novedades bibliográficas, comentaba los anuncios propios y ajenos, denunciaba plagios y errores, etc.".54

Gran parte de los escritos de Prat Gaballí vieron la luz en las páginas de la revista La Propaganda a través de artículos de temáticas genéricas como: "La publicidad en la prensa"55, "Apelación a los sentidos por medio de las imágenes"56, "La publicidad para damas"57, "La publicidad y sus medios: las vallas en el campo"58 y "Ética y cooperación. La Propaganda"59. En 1927, Prat Gaballí como representante de los productos Gal en la zona de Cataluña y Baleares, colaboró en la revista órgano de dicha Perfumería con tres artículos publicados bajo el epígrafe "Ecos de Cataluña"60 y otro titulado "Cinco decálogos".61 La publicación Crisol, diario de la República dirigido por Féliz Lorenzo, recogió sus reivindicaciones en dos artículos titulados "Alrededor de una loable iniciativa del Ministro de Instrucción Pública"62 como reacción ante la reciente creación de facultades de economía en Madrid y Barcelona y el anuncio de la reforma de las enseñanzas mercantiles. Alrededor de 1931, Prat Gaballí, desde Madrid, también colaboró en la revista Publicitat (Butlletí de l'Institut Psicotècnic de la Generalitat de Catalunya) editada por el Seminario de Publicidad del Institut Psicotècnic.63

\footnotetext{
48 PRAT GABALLÍ, Pedro. “Los albores de una técnica. La publicidad en Cataluña”, Mundo Gráfico, n 1104 (1932).

49 PRAT GABALLÍ, Pedro. "La información mercantil en España”, Comercio, n ${ }^{\circ} 1$ (1913).

50 PRAT GABALLÍ, Pedro. “Enseñanzas de una Exposición Internacional de la Publicidad de Londres de 1914”, Comercio, núm. 3 (1913).

51 BARJAU, Santi. “Los inicios del pensamiento publicitario: Pere Prat Gaballí, Rafael Borí y el ‘Publi Club’. La teoría y la práctica de la publicidad 'racional' en Cataluña entre 1915 y 1939”, Publifilia, nº 6 (2002), pp. 49-64, p. 53.

52 PRAT GABALLÍ, Pedro. “El arte de Roberto Cares”, Fama, (1919).

53 PRAT GABALLÍ, Pedro. “Demasiados anuncios”, Fama, (1923).

54 BARJAU, Santi. “Los inicios del pensamiento publicitario: Pere Prat Gaballí, Rafael Borí y el ‘Publi Club’. La teoría y la práctica de la publicidad 'racional' en Cataluña entre 1915 y 1939”, Publifilia, núm. 6 (2002), pp. 49-64, p. 55.

55 PRAT GABALLÍ, Pedro. “La publicidad en la prensa”, La Propaganda, no 7 (1919).

56 PRAT GABALLÍ, Pedro. “Apelación a los sentidos por medio de las imágenes", La Propaganda, nº 16 (1920).

57 PRAT GABALLÍ, Pedro. "Publicidad para damas", La Propaganda, n 18 (1920).

58 PRAT GABALLÍ, Pedro. “La publicidad y sus medios: las vallas en el campo”, La Propaganda, nº 23 (1920).

59 PRAT GABALLÍ, Pedro. “Ética y cooperación. La propaganda”, La Propaganda, no 24 (1920).

60 PRAT GABALLÍ, Pedro. “Ecos de Cataluña (I)”, Pompas de jabón, no 2 (1927), pp. 20-21.

PRAT GABALLÍ, Pedro. “Ecos de Cataluña (II)”, Pompas de jabón, no 4 (1927), pp. 3-4.

PRAT GABALLÍ, Pedro. “Ecos de Cataluña (III)”, Pompas de jabón, no 8 (1927), pp. 3-4.

61 PRAT GABALLÍ, Pedro. “Cinco decálogos”, Pompas de jabón, no 14 (1928), pp. 1-3.

62 PRAT GABALLÍ, Pedro. “Alrededor de una loable iniciativa del Ministro de Instrucción Pública”, Crisol, n 142 (1931), p. 8.
}

PRAT GABALLÍ, Pedro. “Alrededor de una loable iniciativa del Ministro de Instrucción Pública”, Crisol, nº 144 (1931), p. 9.

63 PRAT GABALLÍ, Pedro. Una nueva técnica. La publicidad científica, Cámara Oficial de Comercio, Industria y Navegación, Barcelona, 1992, p.9. 
En 1932, publicó en la revista Mundo Gráfico una reflexión sobre los inicios de la actividad publicitaria en Cataluña titulado "Los albores de una técnica. La publicidad en Cataluña",64 un escrito de gran utilidad que relata el asentamiento de los cimientos de la profesión en España, ensalzando el papel de Cataluña como precursora. De mayor especificidad son los siguientes artículos publicados en Nuevo Mundo en la sección La lucha económica: "Adaptación necesaria de la producción al consumo"65 sobre la necesidad de equilibrio entre la actividad comercial y la demanda, "Los poemas de la luz en la ciudad comercial"66 sobre la publicidad luminotécnica; "La enseñanza de la publicidad"67 en torno a la docencia de la disciplina publicitaria en universidades alemanas; "Aspectos de la crisis en América"68 sobre las causas que motivaron el hundimiento de la economía estadounidense; "El control de la técnica"69 que versa sobre la política económica que la República debería articular; en el artículo "Los quince"70 realiza propuestas de racionalización de la economía al recién creado Consejo de los Quince; "Datos para el Consejo Ordenador de la Economía Nacional"7l en el que solicita el encauzamiento de la eficacia de la inversión publicitaria española mediante la elaboración y publicación de datos estadísticos que permitan su optimización; "Las marcas de garantía"72 referente a los beneficios del fomento de las industrias de marca como sustento de la economía nacional; "Aspectos sociales de la publicidad"73 en torno a una campaña emprendida por la Dirección General de Sanidad para prevenir la mortalidad infantil; "La publicidad como función de Estado. Estudio en el extranjero"74 en que reivindica un mayor interés por parte del Estado en el impulso de la disciplina publicitaria, "Publicidad parasitaria"75 referente a la necesidad de optimizar la inversión publicitarias para evitar la saturación del público y el gasto superfluo por parte de las empresas y "Claude C. Hopkins, el escritor de anuncios que llegó a cobrar cien mil dólares anuales por sus servicios"76 en el que ensalza la obra My life in advertising con motivo de la reciente muerte de este autor al que Prat profesaba profunda admiración y respeto. En 1933, Prat publicó en esta revista generalista "El arte y la publicidad"77 y la segunda parte de este artículo que llevaba por título "Arte y publicidad"78. En estos artículos, Prat instiga a los artistas publicitarios a trascender la naturaleza decorativa y estética de su labor para ejercer una influencia psicológica en el potencial comprador. En ese mismo año, en "El estudio de mercados"79 loa la iniciativa del Instituto de Estudios Comerciales de Barcelona por la introducción de las enseñanzas de Estudio de Mercado y Publicidad.

El profesor Eguizábal señala que en 1934, Prat escribió un artículo con motivo de las exequias de Claude C. Hopkins e indica que probablemente este artículo pudo servirle de base para el último capítulo de su libro El poder de la publicidad dedicado íntegramente a este autor. ${ }^{80}$

En 1936, publicó "La publicidad comercial e industrial" en el número del 15 de octubre de Mi Revista editada en Barcelona, artículo en el que reflexionaba sobre la situación de la publicidad en el contexto de la nueva economía antifascista. En 1937, apareció "La enseñanza de la publicidad" en la revista Nova Iberia editada por el Comisariat de Propaganda de la Generalitat de Catalunya, un artículo que se recicló como presentación de un curso de perfeccionamiento profesional organizado por el Sindicat d'Agents i Tècnics de Publicitat (la antigua Associació d'Agents Professionals de Publicitat) desarrollado entre el 15 de marzo y junio de 1937 en el que Prat Gaballí impartió la materia "Psicología y técnica". En 1941, reivindicó la "Necesidad de estadísticas" en el número 10 del Boletín del Sindicato Mercantil, correspondiente al mes de septiembre y en 1952, disertará sobre la importancia de la dimensión gráfica y compositiva de la publicidad en "El arte publicitario y la tipografía"81 concebido para la revista Gráficas de Madrid.

Por último, en las páginas de la revista especializada en publicidad Arte Comercial vieron la luz artículos como: "La publicidad debe estudiarse en un congreso"82, "Cómo fue creada una costumbre"83, "Los precios y la

64 PRAT GABALLÍ, Pedro. “Los albores de una técnica. La publicidad en Cataluña”, Mundo Gráfico, nº 1104 (1932).

65 PRAT GABALLÍ, Pedro. “Adaptación necesaria de la producción al consumo”, Nuevo Mundo, n 1965 (1931).

66 PRAT GABALLÍ, Pedro. "Los poemas de la luz en la ciudad comercial”, Nuevo Mundo, no 1967 (1931).

67 PRAT GABALLÍ, Pedro. “La enseñanza de la publicidad”, Nuevo Mundo, no 1971 (1931).

68 PRAT GABALLÍ, Pedro. “Aspectos de la crisis en América”, Nuevo Mundo, no 1974 (1932).

69 PRAT GABALLÍ, Pedro. “El control de la técnica”, Nuevo Mundo, nº 1991 (1932).

70 PRAT GABALLÍ, Pedro. “Los quince”, Nuevo Mundo, nº 1992 (1932).

71 PRAT GABALLÍ, Pedro. “Datos para el Consejo Ordenador de la Economía Nacional”, Nuevo Mundo, nº 1995 (1932).

72 PRAT GABALLÍ, Pedro. “Las marcas de garantía”, Nuevo Mundo, nº 1999 (1932).

73 PRAT GABALLÍ, Pedro. “Aspectos sociales de la publicidad”, Nuevo Mundo, no 2001 (1932).

${ }^{74}$ PRAT GABALLÍ, Pedro. "La publicidad como función de Estado. Estudio en el extranjero", Nuevo Mundo, n 2012 (1932).

75 PRAT GABALLÍ, Pedro. “Publicidad parasitaria”, Nuevo Mundo, no 2014 (1932).

76 PRAT GABALLÍ, Pedro. “Claude C. Hopkins, el escritor de anuncios que llegó a cobrar cien mil dólares anuales por sus servicios", Nuevo Mundo, no 2019 (1932).

77 PRAT GABALLÍ, Pedro. “El arte y la publicidad”, Nuevo Mundo, nº 2026 (1933).

78 PRAT GABALLÍ, Pedro. “Arte y publicidad”, Nuevo Mundo, nº 2029 (1933).

79 PRAT GABALLÍ, Pedro. “El estudio de mercados”, Nuevo Mundo, no 2053 (1933).

80 EGUIZÁBAL, Raúl. “Cronología de Pere Prat Gaballí”, Publifilia, no 6 (2002), pp. 123-128, p. 126.

81 PRAT GABALLÍ, Pedro. "El arte publicitario y la tipografía”, Gráficas, (1952).

82 PRAT GABALLÍ, Pedro. “La publicidad debe estudiarse en un congreso”, Arte Comercial, no 16 (1949). 
competencia desleal"84 junto con el más bello homenaje a su amigo y colaborador Federico Ribas, recién fallecido, en un escrito titulado simplemente "Ribas". 85 En él, logró sintetizar en tan sólo dos páginas todo lo que Ribas fue: un trabajador infatigable, un excepcional colaborador y un dibujante irrepetible.

En 1957, publicó dos artículos en los ejemplares inaugurales de Publicidad y Venta: "Perspectiva española para la mercadología: abaratamiento de los productos" 86 y "Necesidad de un Sindicato de la Publicidad". ${ }^{87}$ Finalmente, las últimas contribuciones de las que tenemos constancia vieron la luz en la bonaerense Revista de Propaganda: "La publicidad y la Unión Europea"88 (1958) y "La publicidad en España. Su evolución en Europa"89 (1960).

Estas contribuciones teóricas cumplieron un doble objetivo: impulsar el progreso técnico, teórico y artístico de la publicidad en España y reivindicar la necesidad de estudios que habilitasen para el ejercicio profesional de esta actividad en sus diversas especialidades.

\subsection{Obra poética}

Este publicitario catalán cultivó la poesía, llegando a publicar diversos libros de este género literario. Con respecto a esta faceta del publicitario, Jordi Garriga apuntaba la existencia de un vínculo entre la vocación poética de Prat Gaballí y su ejercicio profesional en el ámbito de la publicidad pues "[...] los productos que mejor se le daban para propagar eran aquellos que poseen, en esencia, una imagen poética: los perfumes y el cava".90

Prat Gaballí formó parte del movimiento modernista catalán que emergió a principios del siglo XX, junto a otras figuras literarias como Joan Maragall, Josep Carner, Gabriel Alomar o Joan Alcover. A continuación, aportamos una crítica literaria datada en 1913 que retrata sus cualidades poéticas:

Prat Gaballí -todavía más joven que Carner- es también un maestro en poesía. Su forma es impecable, su inspiración delicada, su sentimiento espontáneo. No posee la ironía de Carner ni tiene en tan sumo grado la galanura de la frase, pero le aventaja en la profundidad del sentimiento. Si osamos decir, no es tan versificador como es poeta. Prat Gaballí dióse á [sic] conocer con un libro que, de una sola vez, le abrió las puertas de la fama: El Templo Abierto. Hay en esta obra composiciones de tal maestría y tan definitivas que por sólo ellas pudo precisarse, para lo futuro, la "manera" del poeta. [...]"1

Prat Gaballí se inició en el campo literario con colaboraciones como redactor en las revistas Auba (1901-1902) y Catalunya Artística (1901), que tendrán continuidad en revistas como Joventut, La Cataluña, Art Jove en la que vieron la luz "Petits Poemes"92 o "Sonets a la somniada"93. También colaboró en publicaciones dedicadas al teatro como Teatralia o Tot Colors -en la que publicó, entre otros, "Aurioles"94- así como en revistas satíricas de la talla de Cu-cut! y Papitu. En junio de 1907, publicó uno de sus poemas en el primer número de la revista Futurisme. El 9 de noviembre de 1908, en el marco del ciclo de conferencias organizado por Nova Empresa de Teatre Català, Prat disertó sobre La llegenda en el teatre95. En 1909, asumió durante un tiempo la dirección de la Plana Literària de El Pobre Català en la que verán la luz escritos como "L'homenatge al Mestre Guimerà". 96 En el terreno de la traducción literaria, nos consta que tradujo el volumen Sganarelle de Molière -Esganarel $i$ l'Amor metge-, según un anuncio publicado en la revista Teatralia. ${ }^{97}$

Entre su temprana obra poética, publicada en catalán, figuran El Temple Obert. Sonets i altres poesies ${ }^{98}$ (1908), Oracions ferventes (1912) y Poemes de la terra i el mar (1912). En 1909, publicó sus relatos en el ejemplar Contes del Vent editado en la biblioteca Patufet con ilustraciones de Junceda. En 1911, participó con otros

83 PRAT GABALLÍ, Pedro. “Cómo fue creada una costumbre”, Arte Comercial, no 27 (1950).

84 PRAT GABALLÍ, Pedro. “Los precios y la competencia desleal”, Arte Comercial, no 36 (1952).

85 PRAT GABALLÍ, Pedro. “Ribas”, Arte Comercial, no 38 (1952), pp. 16-17.

86 PRAT GABALLÍ, Pedro. "Perspectiva española para la mercadología: abaratamiento de los productos", Publicidad y Venta, $\mathrm{n}^{\circ} 1$ (1957).

87 PRAT GABALLÍ, Pedro. "Necesidad de un Sindicato de la Publicidad”, Publicidad y Venta, no 2 (1957).

88 PRAT GABALLÍ, Pedro. “La publicidad y la Unión Europea”, Revista de Propaganda, no 273 (1958).

89 PRAT GABALLÍ, Pedro. “La publicidad en España. Su evolución en Europa”, Revista de Propaganda, n 289 (1960).

90 PRAT GABALLÍ, Pedro. Una nueva técnica. La publicidad científica, Cámara Oficial de Comercio, Industria y Navegación, Barcelona, 1992, p. 7.

91 BERNADAS, R. “Poetas catalanes contemporáneos”, Mundial Magazine, vol. III, no 13 (1912), pp. 31-39, p. 38.

92 PRAT GABALLÍ, Pedro. “Petits poemes", Art Jove, nº 13 (1906).

93 PRAT GABALLÍ, Pedro. "Sonets a la somniada", Art Jove, nº 3 (1906).

94 PRAT GABALLÍ, Pedro. “Aurioles”, Tot Colors, nº 12 (1908), pp. 184-186.

95 GALLÉN, Enric. “Enquesta sobre'l teatre en vers. A Teatralia (1908-1909): Estudi i Edició”, Estudis Romànics, vol. 31 (2009), pp. 183-218, p. 186.

96 PRAT GABALLÍ, Pere. L'homenatge al Mestre Guimerà, El Poble Català, (03-03-1909).

97 Ídem. Anuncio publicado en un ejemplar de Teatralia (30-09-1908), p. 62.

98 PRAT GABALLÍ, Pedro. El Temple Obert. Sonets i altres poesies, Joaquim Horta, Barcelona, 1908. 
autores en el Almanach del Noucentistes con el poema De l'amor. Según afirma Barjau, este Almanach ha sido mitificado como manifiesto de la corriente cultural conocida como Noucentisme, aunque no deja de ser un almanaque de propaganda de la imprenta Joaquim Horta, a la que Prat Gaballí parece muy vinculado profesionalmente. 99

Parte de sus aportaciones literarias se pueden encontrar en la Antología de poetes catalans moderns ${ }^{100}$ (1914) de Alejandro Plana. Cuando se publicó esta antología, Plana señalaba que Prat Gaballí estaba en proceso de elaboración de Cançons de la vida nova, un volumen que desconocemos si llegó a ser publicado. En cuanto a los cenáculos literarios que frecuentaba, Plàcid Vidal lo vinculaba en su libro Els singulars anecdòtics ${ }^{101}$ a los jóvenes artistas y poetas que se reunían en la célebre cervecería Le Quatre Gats entre los que se hallaban Puig i Ferreter, Isidro Nonell, Hortensi Güell, Alfons Maseras o Josep M. de Sucres. ${ }^{102}$

En 1932, publicó X-HP Poemes, una obra poética de carácter vanguardista con referencias a la modernidad simbolizada a través de la máquina de tren, el automóvil, la velocidad, el cine, la luz eléctrica, el avión y las fábricas. Y por último, ya en la fase final de su existencia, escribió Moments (1962).

Si bien es cierto que a partir de 1911. Prat Gaballí se dedicó enteramente a su faceta comercial y publicitaria, nunca dejó de cultivar la poesía. Esta afición literaria que nunca abandonó es una muestra más de la excepcionalidad de este profesional capaz de escribir emotivos poemas así como rigurosos manuales publicitarios.

\section{Conferencias y ponencias}

Prat Gaballí extendió su magisterio en diversos congresos dentro y fuera de las fronteras nacionales. El 31 de julio de 1929, en el I Congreso Nacional de Publicidad celebrado en Barcelona, Prat Gaballí expuso la ponencia "Publicidad y mercado". Al año siguiente, en el seno del II Congreso impartió la conferencia "Posibilidades de la publicidad en el actual momento económico".

En julio de 1932, presentó su ponencia "Study of the markets for a popular commodity, the sale of which must be affected by publicity"103 en el Vth International Congress for Scientific Management que tuvo lugar en Ámsterdam. En esta separata editada por la Perfumería Gal,104 Prat Gaballí figura en primer lugar como director de la Agencia Veritas, S.A., Madrid seguido de numerosos méritos que reproducimos literalmente:

Director of the Agencia Veritas, S.A., Madrid.- Professor of Advertising and Marketing (Chamber of Commerce, Barcelona, 1915-16-17).- First President and President of Honour of Publi-Club.- Vice-president of the Executive Comittee of the Ist Nacional Advertising Convention, Barcelona, 1929 and Chairman of the 2nd Nacional Advertising Convention, Madrid, 1930.- Author of "La Publicidad científica" and "Técnica de la Publicidad".

En 1933, publicó el fascículo "Historia documentada de una campaña educativa" editado por la Perfumería Gal en el que explicaba los pormenores de la emblemática campaña educativa para el dentífrico Dens. Tras la guerra civil, en el III Congreso Nacional de Artes Gráficas celebrado en Barcelona del 19 al 24 de junio de 1950, Prat Gaballí, como presidente del Círculo Publicitario, presentó su conferencia "Elogio de las artes gráficas" que fue pronunciada en el Salón de Actos de la Biblioteca de Cataluña en el acto inaugural de la II Exposición Nacional Monográfica del Arte Impreso celebrada en el marco del citado congreso.

El 16 de octubre de 1950 leyó su discurso "Propaganda y Opinión Pública. La reeducación de las masas" en la conferencia inaugural del Círculo Publicitario de Barcelona que presidía. El 4 de mayo de 1952, pronunció el discurso inaugural de la Semana Mundial de la Publicidad que tuvo lugar en la Cámara de Comercio y Navegación de Barcelona. En mayo de 1961, impartió su conferencia "La palabra y la actuación en las ventas" en la Escuela de Estudios Universitarios de Guipúzcoa en San Sebastián. Y en septiembre de ese mismo año, Prat relató "Cooperación mercadológica en Europa" en el marco del IV Conferencia Europea de la I.A.A. celebrada en Madrid.

El día 8 de junio de 1962, Prat Gaballí regresó al punto de partida, a un lugar muy representativo en su vida, aquel que le había brindado la primera oportunidad y en el que había dado comienzo su andadura como docente, la Casa Lonja del Mar, para pronunciar "La publicidad comercial española en la hora del desarrollo económico". En esta ocasión, ya en el ocaso de su carrera profesional y de su existencia es presentado como: "Profesor de Publicidad y Mercadología y Vocal cooperador de la Cámara Oficial de Comercio y Navegación

99 BARJAU, Santi. “Los inicios del pensamiento publicitario: Pere Prat Gaballí, Rafael Borí y el 'Publi Club'. La teoría y la práctica de la publicidad 'racional' en Cataluña entre 1915 y 1939", Publifilia, nº 6 (2002), pp. 49-64, p. 51.

100 PLANA, Alexandre. Antologia de poetes catalans moderns, Societat Catalana D'Edicions, Barcelona, 1914, pp. $219-225$. 101 VIDAL, Plàcid. Els singulars anecdòtics, Joaquim Horta, Barcelona, 1920, p. 57-60.

102 BARJAU, Santi. “Los inicios del pensamiento publicitario: Pere Prat Gaballí, Rafael Borí y el ‘Publi Club’. La teoría y la práctica de la publicidad 'racional' en Cataluña entre 1915 y 1939”, Publifilia, nº 6 (2002), pp. 49-64, p. 49.

103 PRAT GABALLÍ, Pedro. "Study of the markets for a popular commodity, the sale of which must be affected by publicity", Congress Book Vth International Congress for Scientific Management, Ámsterdam, vol. I (1932), pp. 3-46 y 50. 104 Ídem. 
de Barcelona". En las páginas interiores de este folleto que contiene la conferencia de Pedro Prat Gaballí, es calificado como "uno de los promotores y mayores impulsores de los estudios sobre publicidad en nuestro país, tanto en el orden técnico como en el científico". 105

\section{Conclusiones}

En suma, tras esta aproximación al patrimonio científico y literario legado por Pedro Prat Gaballí, estamos en condiciones de concluir que nos hallamos ante uno de los autores y profesionales españoles más dinámicos e influyentes de la historia de la publicidad española al proporcionar con sus contribuciones una base teórica sólida a una disciplina que adolecía de rigor académico. Sus manuales y escritos han aportado una suma de literatura científica sobre psicología experimental aplicada a la publicidad y técnica en la planificación y dirección de campañas publicitarias sin precedentes en España.

Por tanto, este artículo revela a Prat Gaballí como un innegable referente de nuestra publicidad al ser el primer estudioso y docente de la materia cuyo magisterio permitió sentar las bases de la nueva técnica publicitaria en España. A él debemos la importación, divulgación y adaptación a nuestro país de los fundamentos de una técnica publicitaria científica, metódica y pragmática que se venía aplicando con éxito en Estados Unidos.

En efecto, Prat aspiraba a equiparar la publicidad española al nivel de la estadounidense mediante la difusión de su vasto saber a través de ponencias, manuales, tratados y artículos que hemos compendiado en la presente investigación. Sus contribuciones atestiguan su excelsa formación -fruto de su vocación, estudio y práctica- y su constante actualización mediante la lectura y asimilación de informes, estudios técnicos y bibliografía publicitaria foránea.

En el ámbito académico, propugnó la implantación de estudios superiores sobre técnica publicitaria en España y la incorporación de esta materia a los planes oficiales de las escuelas mercantiles estatales. Por tanto, las facultades españolas con títulos de grado y postgrado en publicidad son, en gran parte, deudoras de la labor de concienciación y de la obstinación de este pionero.

En suma, la totalidad de su actividad docente, teórica y profesional en sus diversas vertientes lo consagran como un técnico y teórico publicitario de gran cultura humanística y económica que trató de sistematizar la técnica publicitaria y se ganó a pulso su autoridad en la materia, una autoridad que, un siglo después, aún sigue vigente.

\section{Bibliografía}

ALVARADO, Ma Cruz y ANDRÉS, Susana de. "El concepto de creatividad en la obra de Pedro Prat Gaballi", Trípodos, nextra (2006), pp. 13-22.

ANDRÉS, Susana de. "Asignatura, contenido editorial y empresa. La publicidad en los preludios de la Guerra Civil", Publifilia, nº (2002), pp. 19-36.

BARJAU, Santi. "Los inicios del pensamiento publicitario: Pere Prat Gaballí, Rafael Borí y el 'Publi Club'. La teoría y la práctica de la publicidad 'racional' en Cataluña entre 1915 y 1939", Publifilia, n 6 (2002), pp. 49-64.

BERNADAS, R., "Poetas catalanes contemporáneos", Mundial Magazine, vol. III, n 13 (1912), pp. 31-39, p. 38.

CARO, Antonio. "Exceso y miseria de la información publicitaria" en EGUIZÁBAL, Raúl y CARO, Antonio (coords.). Medición, Investigación e información de la publicidad, Edipo, Madrid, 1996.

EGUIZÁBAL, Raúl. "El arte al servicio de la técnica", Publifilia, nº 6 (2002), pp. 65-68.

EGUIZÁBAL, Raúl. "Cronología de Pere Prat Gaballí", Publifilia, nº 6 (2002), pp. 123-128.

EGUIZÁBAL, Raúl. "Cuatro siluetas publicitarias", Academia de la Publicidad, (2009).

URL [http://www.academiadelapublicidad.org/index.php/colaboraciones-actualidad-y-archivo/histórico] [Consultado 14-05-2011].

GALLÉN, Enric. "Enquesta sobre'l teatre en vers. A Teatralia (1908-1909): Estudi i Edició", Estudis Romànics, vol. 31 (2009), pp. 183-218.

GARRIGA, Jordi. "Veinte años después", Control de publicidad y ventas, n² 235 (1982), p. 13-21.

GARRIGA, Jordi et. al. Pedro Prat Gaballí. 505 verdades publicitarias, Oikos-Tau, Barcelona, 1998.

HERREROS, Mario. "Pere Prat Gaballí (1885-1962): Ante el septuagésimo aniversario de su nombramiento como primer Catedrático Universitario de Publicidad", Revista Universitaria de Publicidad y Relaciones Públicas, $n^{\circ} 3$ (1996), pp. 35-65.

HOPKINS, Claude C. Mi vida en la publicidad, Dalmau y Jover, Barcelona, 1945.

IZQUIERDO, Francisco. "Mi personaje inolvidable Don Pedro Prat Gaballi", Control de Publicidad y Ventas, $\mathrm{n}^{\circ}$ 235 (1982), pp. 7-9.

PLANA, Alexandre. Antologia de poetes catalans moderns, Societat Catalana D'Edicions, Barcelona, 1914.

PRAT GABALLÍ, Pedro. "Petits poemes", Art Jove, n 13 (1906).

PRAT GABALLÍ, Pedro. "Sonets a la somniada", Art Jove, n 3 (1906).

PRAT GABALLÍ, Pedro. El Temple Obert. Sonets i altres poesies), Joaquim Horta, Barcelona, 1908.

105 PRAT GABALLÍ, Pedro. "La publicidad comercial española en la hora del desarrollo económico", Cámara Oficial de Comercio y Navegación, Barcelona, 1962. 
PRAT GABALLÍ, Pere. L'homenatge al Mestre Guimerà, El Poble Català, (03-03-1909).

PRAT GABALLÍ, Pedro. "La información mercantil en España", Comercio, n 1 (1913).

PRAT GABALLí, Pedro. "Enseñanzas de una Exposición Internacional de la Publicidad de Londres de 1914", Comercio, n 3 (1913).

PRAT GABALLÍ, Pedro. L'ensenyament comercial i la formació de vendedors hàbils, Sabadell, P. Montaner, 1917.

PRAT GABALLÍ, Pedro. "La publicidad en la prensa", La Propaganda, nº 7 (1919).

PRAT GABALLÍ, Pedro. "El arte de Roberto Cares", Fama, (1919).

PRAT GABALLÍ, Pedro. "Demasiados anuncios", Fama, (1923).

PRAT GABALLÍ, Pedro. "Apelación a los sentidos por medio de las imágenes", La Propaganda, n 16 (1920).

PRAT GABALLÍ, Pedro. "Publicidad para damas", La Propaganda, n 18 (1920).

PRAT GABALLÍ, Pedro, "La publicidad y sus medios: las vallas en el campo", La Propaganda, n²3 (1920).

PRAT GABALLÍ, Pedro, "Ética y cooperación. La propaganda", La Propaganda, núm. 24, octubre de 1920, año III.

PRAT GABALLÍ, Pedro. "El primer club español de publicidad", Pompas de jabón, n 6 (1927), pp. 7-8.

PRAT GABALLÍ, Pedro. "Adaptación necesaria de la producción al consumo", Nuevo Mundo, n 1965 (1931).

PRAT GABALLÍ, Pedro. "Los poemas de la luz en la ciudad comercial", Nuevo Mundo, n 1967 (1931).

PRAT GABALLÍ, Pedro. "La enseñanza de la publicidad", Nuevo Mundo, n 1971 (1931).

PRAT GABALLÍ, Pedro. "Alrededor de una loable iniciativa del Ministro de Instrucción Pública", Crisol, n 142 (1931), p. 8.

PRAT GABALLÍ, Pedro. "Alrededor de una loable iniciativa del Ministro de Instrucción Pública", Crisol, n 144 (1931), P. 9.

PRAT GABALLÍ, Pedro. "Aspectos de la crisis en América", Nuevo Mundo, n 1974 (1932).

PRAT GABALLÍ, Pedro. "El control de la técnica", Nuevo Mundo, nº 1991 (1932).

PRAT GABALLÍ, Pedro, "Los quince", Nuevo Mundo, nº 1992 (1932).

PRAT GABALLÍ, Pedro. "Datos para el Consejo Ordenador de la Economía Nacional", Nuevo Mundo, nº 1995 (1932).

PRAT GABALLÍ, Pedro. "Los albores de una técnica. La publicidad en Cataluña", Mundo Gráfico, n 1104 (1932).

PRAT GABALLÍ, Pedro. "Las marcas de garantía", Nuevo Mundo, nº 1999 (1932).

PPRAT GABALLÍ, Pedro. "Aspectos sociales de la publicidad", Nuevo Mundo, $\mathrm{n}^{\circ} 2001$ (1932).

PRAT GABALLÍ, Pedro. "La publicidad como función de Estado. Estudio en el extranjero", Nuevo Mundo, n 2012 (1932).

PRAT GABALLÍ, Pedro. "Publicidad parasitaria", Nuevo Mundo, n² 2014 (1932).

PRAT GABALLÍ, Pedro. "Claude C. Hopkins, el escritor de anuncios que llegó a cobrar cien mil dólares anuales por sus servicios", Nuevo Mundo, n² 2019 (1932).

PRAT GABALLÍ, Pedro. "El arte y la publicidad", Nuevo Mundo, n² 2026 (1933).

PRAT GABALLÍ, Pedro. "Arte y publicidad", Nuevo Mundo, nº 2029 (1933).

PRAT GABALLÍ, Pedro. "El estudio de mercados", Nuevo Mundo, n 2053 (1933).

PRAT GABALLÍ, Pedro. "Study of the markets for a popular commodity, the sale of which must be affected by publicity", Congress Book Vth International Congress for Scientific Management, Ámsterdam, vol. I (1932), pp. 346 y 50.

PRAT GABALLÍ, Pedro. Publicidad Racional, Barcelona, Labor, 1934.

PRAT GABALLÍ, Pedro. El poder de la publicidad, Barcelona, Juventud, 1939.

PRAT GABALLÍ, Pedro. "El arte publicitario y la tipografía", Gráficas, (1952).

PRAT GABALLÍ, Pedro. "La publicidad debe estudiarse en un congreso", Arte Comercial, n 16 (1949).

PRAT GABALLÍ, Pedro. "Cómo fue creada una costumbre", Arte Comercial, n 27 (1950).

PRAT GABALLÍ, Pedro. "Los precios y la competencia desleal", Arte Comercial, n 36 (1952).

PRAT GABALLÍ, Pedro, "Ribas", Arte Comercial, n 38 (1952), pp. 16-17.

PRAT GABALLÍ, Pedro. "Perspectiva española para la mercadología: abaratamiento de los productos", Publicidad y Venta, $n^{\circ} 1$ (1957).

PRAT GABALLÍ, Pedro. "Necesidad de un Sindicato de la Publicidad", Publicidad y Venta, nº 2 (1957).

PRAT GABALLÍ, Pedro. "La publicidad y la Unión Europea", Revista de Propaganda, n² 273 (1958).

PRAT GABALLí, Pedro. "La publicidad en España. Su evolución en Europa", Revista de Propaganda, n² 289 (1960).

PRAT GABALLÍ, Pedro. Publicidad Combativa, Barcelona, Labor, 1959.

PRAT GABALLII, Pedro. "La publicidad comercial española en la hora del desarrollo económico", Cámara Oficial de Comercio y Navegación, Barcelona, 1962.

PRAT GABALLÍ, Pedro. Una nueva técnica. La publicidad científica, Cámara Oficial de Comercio, Industria y Navegación, Barcelona, 1992. Edición 75 aniversario.

"Pedro Prat Gaballí en el recuerdo. Jordi Prat Ballester: La fidelidad a un nombre", Control del publicidad y ventas, $n^{\circ} 235$, p. 25.

ROM, Josep et. al. "El legado de Pedro Prat Gaballí: las raíces de la publicidad moderna".

http://web.me.com/romjosep/ep/page4/page26/page96/files/page96_1.pdf [Consultado 07-06-2011]

TAYLOR, F.W. Economía publicitaria, Juventud, Barcelona, 1939. 
VIDAL, Plàcid, Els singulars anecdòtics, Joaquim Horta, Barcelona, 1920.

VV.AA. Curso de Publicidad y Organización, Cultura, Barcelona, 1928.

VV.AA. Enciclopedia Universal llustrada Europeo Americana, Hijos de Espasa Editores, Barcelona, 1922, Tomo XLVI, p. 1279. 